\title{
Prognostic abilities of different calculation formulas for the glomerular filtration rate in elderly Chinese patients with coronary artery disease
}

This article was published in the following Dove Press journal:

Clinical Interventions in Aging

18 February 2013

Number of times this article has been viewed

\section{Shihui Fu \\ Yuan Liu \\ Bing Zhu \\ Tiehui Xiao \\ Shuangyan $\mathrm{Yi}$ \\ Yongyi Bai \\ Ping Ye \\ Leiming Luo}

Department of Geriatric Cardiology, Chinese PLA General Hospital, Beijing, People's Republic of China
Correspondence: Leiming Luo Department of Geriatric Cardiology, Chinese PLA General Hospital, Fuxing Road 28, Haidian District, Beijing 100853, People's Republic of China

Tel +861088626362

Fax +861066876349

Email lleim@sina.com
Objective: As a standard indicator of renal function, the glomerular filtration rate (GFR) is vital for the prognostic analysis of elderly patients with coronary artery disease (CAD). Thus, the search for the calculation equation of GFR with the best prognostic ability is an important task. The most commonly used Modification of Diet in Renal Disease (MDRD) equation and the Chinese version (CMDRD) of the MDRD equation has many shortcomings. The newly developed Mayo Clinic quadratic (Mayo) and Chronic Kidney Disease (CKD) Epidemiology Collaboration (CKD-EPI) equations may overcome these shortcomings. Because the populations involved in these equation-related studies are almost completely devoid of subjects $>70$ years of age, there are more debates on the performance of these equations in the elderly. This study was designed to compare the prognostic abilities of different calculation formulas for the GFR in elderly Chinese patients with CAD.

Methods: This study included 1050 patients ( $\geq 60$ years of age) with CAD. The endpoint was all-cause mortality over a mean follow-up period of 417 days.

Results: The median age was 86 years (60-104 years). The median values for the MDRDGFR, CMDRD-GFR, CKD-EPI-GFR, and Mayo-GFR were 66.0, 69.2, 65.6, and $75.8 \mathrm{~mL} /$ minute $/ 1.73 \mathrm{~m}^{2}$, respectively. The prevalence of GFR $<60 \mathrm{~mL} /$ minute $/ 1.73 \mathrm{~m}^{2}$ based on these measures was $39.3 \%, 35.4 \%, 43.0 \%$, and $28.7 \%$, respectively. Their area under the curve values for predicting death were $0.611,0.610,0.625$, and 0.632 , respectively. Their cut-off points for predicting death were $54.1,53.5,48.0$, and $57.4 \mathrm{~mL} /$ minute $/ 1.73 \mathrm{~m}^{2}$, respectively. Compared with the MDRD-GFR, the net reclassification improvement values of the CMDRD-GFR, CKDEPI-GFR, and Mayo-GFR were $0.02,0.10$, and 0.14 , respectively.

Conclusion: The prognostic abilities of the CKD-EPI and Mayo equations were significantly superior to the MDRD and CMDRD equations; the Mayo equation had a mild, but not statistically significant superiority compared with the CKD-EPI equation in elderly Chinese patients with CAD.

Keywords: chronic kidney disease, coronary artery disease, glomerular filtration rate, equation, elderly

\section{Introduction}

On a global scale, evolving changes in demographics have led to an aging population, along with an increasing prevalence of renal function impairment in patients with coronary artery disease (CAD). ${ }^{1}$ The latter might result in a higher mortality rate. ${ }^{2-4}$ Thus, as the standard indicator of renal function, the glomerular filtration rate (GFR) is vital for the prognostic analysis of elderly patients with CAD. To search for the calculation equation of GFR derived from serum creatinine (Scr) with the best prognostic ability is therefore an important task. The poorer prognostic ability of the most commonly used Modification of 
Diet in Renal Disease (MDRD) study equation in subjects with an elevated GFR, such as women, younger, and white subjects without comorbidities, has been well-established..$^{5-7}$ The newly developed Mayo Clinic quadratic (Mayo) and Chronic Kidney Disease (CKD) Epidemiology Collaboration (CKD-EPI) equations consist of the same four variables as the MDRD equation, but may have better prognostic ability. ${ }^{8-10}$ Race is an important determinant of the GFR calculation. Unfortunately, Asians have not been included in MDRD and CKD-EPI studies; thus the Chinese MDRD (CMDRD) equation is based on the original MDRD equation for use in Chinese patients, ${ }^{11}$ but there is still no modification of the CKD-EPI equation in the People's Republic of China. The populations involved in these equationrelated studies were almost completely devoid of subjects $>70$ years of age, subjects who are known to have the greatest burden of GFR-related adverse outcomes. ${ }^{8,9}$ Therefore, debates on the performance of these equations in the elderly continue.

Currently, there is no study that has compared the four equations in populations composed mainly of the elderly, men, and Chinese with CAD, as opposed to women, younger, and white subjects without comorbidities. Since these formulas may not perform equally in different subjects, the comparison made between the formulas depends on the subjects under study. ${ }^{12}$ The current study was designed to compare the prognostic abilities of different calculation formulas for the GFR in elderly Chinese patients with CAD.

\section{Methods}

\section{Population}

Patients $\geq 60$ years of age who were diagnosed with CAD were enrolled in this study. The diagnosis was based on history, symptoms of typical angina, cardiac markers, and specific cardiac examinations, such as an electrocardiogram (resting/ exercise), echocardiography, radionuclide imaging, computed tomography, and coronary arteriography, and was performed by chief physicians or associate chief physicians according to the American College of Cardiology/American Heart Association (ACC/AHA) and European Society of Cardiology (ESC) guidelines. ${ }^{13,14}$ The exclusion criteria included severe aortic stenosis, anticipated cardiac transplantation, and use of a left ventricular assist device. The current study was comprised of 1050 cases, on which the following analysis was based. The Chinese People's Liberation Army General Hospital was the designated hospital for all patients, and had integrated longterm medical and final death records, which made it easier for us to follow up effectively and judge endpoints accurately. The study protocol was approved by the local Ethics Committee and in accordance with the Helsinki Declaration of 1975 (as revised in 1983).

\section{Baseline variables}

All information was carefully obtained, preserved, and verified by trained researchers. The basic characteristics included demographics (age and gender) and physical examination findings (mean systolic blood pressure). The body mass index was defined as the weight in kilograms divided by the square of the height in meters. The Scr concentration was measured using an enzymatic method, and the calibration formula was as follows: ${ }^{15}$

Jaffe's kinetic method:

$$
\begin{aligned}
\operatorname{Scr}(\mathrm{mg} / \mathrm{dL})= & 0.795 \times[\text { enzymatic method Scr } \\
& (\mathrm{mg} / \mathrm{dL})]+0.29
\end{aligned}
$$

The enzymatic method Scr was used in the CKD-EPI formula, and the Jaffe's kinetic method Scr was used in the other three formulas. The GFR of all 1050 subjects was evaluated with different equations as follows.

MDRD formula: ${ }^{5}$

$$
\begin{aligned}
\operatorname{MDRD}= & 186 \times \operatorname{Scr}(\mathrm{mg} / \mathrm{dL})^{-1.154} \\
& \times \text { age }(\text { years })^{-0.203} \times 0.742(\text { if female })
\end{aligned}
$$

Chinese MDRD formula: ${ }^{11}$

$$
\begin{aligned}
\mathrm{CMDRD}= & 175 \times \mathrm{Scr}(\mathrm{mg} / \mathrm{dL})^{-1.234} \\
& \times \text { age }(\text { year })^{-0.179} \times 0.79(\text { if female })
\end{aligned}
$$

Mayo Clinic quadratic formula: ${ }^{10}$

$$
\begin{aligned}
\text { Mayo }= & \exp [1.911+5.249 / \mathrm{Scr}(\mathrm{mg} / \mathrm{dL}) \\
& -2.114 / \mathrm{Scr}(\mathrm{mg} / \mathrm{dL})^{2}-0.00686 \\
& \times \text { age }(\text { years })-0.205(\text { if female })]
\end{aligned}
$$

\section{CKD-EPI formula ${ }^{8}$}

If female and if Scr $\leq 0.7 \mathrm{mg} / \mathrm{dL}$ :

$$
\begin{aligned}
\mathrm{CKD}-\mathrm{EPI}= & 144 \times \mathrm{Scr}(\mathrm{mg} / \mathrm{dL}) / 0.7^{-0.329} \\
& \times 0.993^{\text {age }} \text { (years) }
\end{aligned}
$$

If female and if Scr $>0.7 \mathrm{mg} / \mathrm{dL}$ :

$$
\begin{aligned}
\mathrm{CKD}-\mathrm{EPI}= & 144 \times \mathrm{Scr}(\mathrm{mg} / \mathrm{dL}) / 0.7^{-1.209} \\
& \times 0.993^{\text {age }(\text { years })}
\end{aligned}
$$

If male and if Scr $\leq 0.9 \mathrm{mg} / \mathrm{dL}$ : 


$$
\begin{aligned}
\mathrm{CKD}-\mathrm{EPI}= & 141 \times \mathrm{Scr}(\mathrm{mg} / \mathrm{dL}) / 0.9^{-0.411} \\
& \times 0.993^{\text {age }(\text { years })}
\end{aligned}
$$

If male and if Scr $>0.9 \mathrm{mg} / \mathrm{dL}$ :

$$
\begin{aligned}
\mathrm{CKD}-\mathrm{EPI}= & 141 \times \mathrm{Scr}(\mathrm{mg} / \mathrm{dL}) / 0.9^{-1.209} \\
& \times 0.993^{\text {age (years) }}
\end{aligned}
$$

\section{Determination of diseases}

Hypertension was considered to be present if the systolic blood pressure was $\geq 140 \mathrm{mmHg}$, the diastolic blood pressure was $\geq 90 \mathrm{mmHg}$, and/or the subject was taking an antihypertensive drug. A subject was considered to have diabetes mellitus if the fasting plasma glucose was $\geq 7.0 \mathrm{mmol} / \mathrm{L}$, the postprandial blood glucose (2-hour venous blood glucose) was $\geq 11.1 \mathrm{mmol} / \mathrm{L}$, and/or the subject was taking a hypoglycemic drug or insulin. Atrial fibrillation (AF) and chronic heart failure (CHF) were defined on the basis of the ACC/AHA/ESC 2006 guideline for $\mathrm{AF}^{16}$ and the ESC 2008 guideline for $\mathrm{CHF},{ }^{17}$ respectively.

\section{Outcome}

Given the priority of all-cause mortality in outcome studies, as well as the high incidence of multiple organ failure in the elderly, all-cause mortality was chosen as the endpoint and was ascertained from death records.

\section{Statistical analysis}

The variables were described by the mean and standard deviation for continuous variables with a normal distribution, the median and 25th-75th percentiles for nonnormally distributed continuous variables, and the percentage of the total for categorical variables. The differences between any two equations were tested by the Wilcoxon signed-rank test. The GFR was divided into six different categories $(>90$, 60-89, 45-59, 30-44, 15-29, and < $15 \mathrm{~mL} /$ minute $/ 1.73 \mathrm{~m}^{2}$ ). The differences between the GFR categories were tested by one-way analysis of variance for continuous variables (normal distribution), the Kruskal-Wallis test for continuous variables (abnormal distribution), and $\mathrm{x}^{2}$ analysis for categorical variables. The correlations between any two equations were determined with Spearman's test. The proportion of patients with a GFR $<60 \mathrm{~mL} /$ minute $/ 1.73 \mathrm{~m}^{2}$ was defined as the prevalence and the differences were examined with a Kappa test.

Not only the receiver-operating characteristic (ROC) curve and area under the curve (AUC) values, but also the net reclassification improvement (NRI), as described by Pencina et $a 1^{18}$ were used to assess the prognostic value of different equations. The best cut-off value of the GFR for predicting mortality was derived from the ROC curve, and was the cutoff point at which the sum of the sensitivity and specificity was the highest. The NRI was calculated as the sum of the proportion of participants reclassified downward to a lower GFR category for people who died and the proportion of participants reclassified upward to a higher GFR category for people who survived, minus the sum of the proportion of participants reclassified upward for people who died and the proportion of participants reclassified downward for people who survived. The $\mathrm{Z}$ statistic was used to compare the c-statistics and to determine the significance of NRI. To judge the independent predictive value of renal function impairment for mortality, covariates with a $P<0.10$ were identified by Cox regression univariate analysis and taken into the multivariate Cox regression model with mortality as the dependent variable, which was divided into two steps, including the backward stepwise (likelihood ratio test) with a $P<0.10$ and enter with a two-tailed $P<0.05$ to avoid collinearity of the variables. The $\beta$ value is the coefficient of variables in the Cox regression model, and the hazard ratio $(\mathrm{HR})$ is the $\exp (\beta)$. Statistical analysis was conducted using the Statistical Package for the Social Sciences 17 (SPSS, Inc, Chicago, IL, USA) and MedCalc 11.6 for Windows (MedCalc Software bvba, Mariakerke, Belgium).

\section{Results}

The median age of the participants was 86 years (60-104 years), and $80.8 \%$ ( 848 patients) of the participants were $>80$ years of age. The majority $(89.2 \%)$ of the participants were male, and all the participants were Chinese (100\%). Table 1 lists the clinical characteristics of the participants at different GFR categories computed using four equations. The median values (25th-75th percentiles) for the MDRD-GFR, CMDRD-GFR, CKD-EPI-GFR, and Mayo-GFR were 66.0 (51.6, 78.0), $69.2(53.3,82.3), 65.6(46.9,80.2)$, and 75.8 $(56.5,88.5) \mathrm{mL} /$ minute $/ 1.73 \mathrm{~m}^{2}$, respectively. The GFR computed by any two equations showed strong correlations (correlation coefficients: MDRD-GFR and CMDRD-GFR: 0.996; MDRD-GFR and CKD-EPI-GFR: 0.980; MDRDGFR and Mayo-GFR: 0.959; CMDRD-GFR and CKD-EPIGFR: 0.987; CMDRD-GFR and Mayo-GFR: 0.955; and CKD-EPI-GFR and Mayo-GFR: 0.963; all $P<0.001$ ). The significant differences in the computed GFR were observed with respect to any two equations (all $P<0.001$ ). As shown in Figure 1A, the GFR determined by each equation decreased as the 10-year age categories increased. 
Table I Clinical characteristics of participants at different GFR categories computed using four equations

\begin{tabular}{|c|c|c|c|c|c|c|c|}
\hline \multirow[t]{2}{*}{ Characteristics } & \multicolumn{6}{|c|}{ GFR categories (mL/minute/l.73 $\left.\mathrm{m}^{2}\right)$} & \multirow[t]{2}{*}{$P$-value } \\
\hline & $>90$ & 60-89 & 45-59 & $30-44$ & $15-29$ & $<\mathbf{1 5}$ & \\
\hline \multicolumn{8}{|l|}{ Age (years) } \\
\hline MDRD & $86.0(81.8-88.3)$ & $85.0(80.0-89.0)$ & $86.0(82.0-90.0)$ & $88.0(83.0-92.0)$ & $87.0(83.0-90.0)$ & $83.5(77.0-87.0)$ & $<0.001$ \\
\hline CMDRD & $85.0(80.0-89.0)$ & $85.0(80.3-89.0)$ & $86.0(83.0-90.0)$ & $88.0(82.5-92.0)$ & $87.0(83.0-90.0)$ & $84.0(77.0-87.0)$ & $<0.001$ \\
\hline CKD-EPI & $78.0(68.0-86.0)$ & $85.0(81.0-89.0)$ & $86.0(83.0-89.0)$ & $88.0(84.0-92.0)$ & $88.0(84.0-91.0)$ & $84.5(77.0-89.0)$ & $<0.001$ \\
\hline Mayo & $83.0(75.0-87.0)$ & $86.0(82.0-90.0)$ & $87.0(84.0-91.0)$ & $88.0(83.0-91.0)$ & $88.0(84.0-91.0)$ & $83.5(77.0-87.5)$ & $<0.001$ \\
\hline \multicolumn{8}{|l|}{ Men (\%) } \\
\hline MDRD & $104(98.1)$ & $480(90.4)$ & $210(87.9)$ & $83(79.0)$ & $33(84.6)$ & $27(90.0)$ & $<0.001$ \\
\hline CMDRD & $150(94.9)$ & $467(89.8)$ & $178(88.6)$ & 81 (80.2) & $33(84.6)$ & $28(90.3)$ & 0.010 \\
\hline CKD-EPI & 7I (94.7) & $470(89.9)$ & $195(89.4)$ & II 0 (85.9) & $54(81.8)$ & $37(92.5)$ & 0.145 \\
\hline Mayo & $229(100.0)$ & $444(85.4)$ & $124(90.5)$ & $68(81.9)$ & $4 \mid(87.2)$ & 31 (9I.2) & $<0.001$ \\
\hline \multicolumn{8}{|l|}{ BMI $\left(\mathrm{kg} / \mathrm{m}^{2}\right)$} \\
\hline MDRD & $23.1(3.5)$ & $23.9(3.4)$ & $24.6(3.6)$ & $23.5(3.4)$ & $23.5(3.4)$ & 23.7 (3.7) & 0.009 \\
\hline CMDRD & $23.3(3.5)$ & $24.0(3.4)$ & $24.5(3.5)$ & $23.5(3.4)$ & $23.2(3.5)$ & $23.7(3.7)$ & 0.017 \\
\hline CKD-EPI & $23.7(3.8)$ & $23.8(3.3)$ & $24.3(3.6)$ & $24.2(3.5)$ & $23.6(3.4)$ & $23.1(3.6)$ & 0.185 \\
\hline Mayo & $23.6(3.1)$ & $24.0(3.6)$ & $24.5(3.6)$ & $23.6(3.2)$ & $23.5(3.6)$ & $23.3(3.8)$ & 0.119 \\
\hline \multicolumn{8}{|l|}{ MSBP $(\mathrm{mmHg})$} \\
\hline MDRD & I32.8 (13.5) & I32.7 (I3.6) & I33.8 (I2.6) & $134.4(13.0)$ & $134.9(13.1)$ & $137.9(14.9)$ & 0.258 \\
\hline CMDRD & $132.2(13.1)$ & $133.0(\mid 3.6)$ & 133.7 (I2.7) & 134.I (13.1) & $135.0(13.1)$ & I37.8 (14.7) & 0.332 \\
\hline CKD-EPI & I3I.7 (I3.5) & I32.6 (I3.5) & I34.4 (I3.I) & I33.6 (I3.I) & $134.0(12.1)$ & I39.1 (I4.2) & 0.040 \\
\hline Mayo & I30.8 (I2.3) & I33.8 (|3.8) & $133.6(\mid 2.7)$ & $134.0(13.4)$ & 134.3 (11.9) & I39.1 (I4.8) & 0.005 \\
\hline \multicolumn{8}{|l|}{ AMI (\%) } \\
\hline MDRD & $5(4.7)$ & $30(5.6)$ & $16(6.7)$ & $13(12.4)$ & $3(7.7)$ & $4(13.3)$ & 0.105 \\
\hline CMDRD & $8(5.1)$ & $27(5.2)$ & $16(8.0)$ & $13(12.9)$ & $2(5.1)$ & $5(16.1)$ & 0.018 \\
\hline CKD-EPI & $5(6.7)$ & $26(5.0)$ & $15(6.9)$ & $14(10.9)$ & $5(7.6)$ & $6(15.0)$ & 0.060 \\
\hline Mayo & $15(6.6)$ & $25(4.8)$ & $13(9.5)$ & $10(12.0)$ & $3(6.4)$ & $5(14.7)$ & 0.037 \\
\hline \multicolumn{8}{|l|}{ CHF (\%) } \\
\hline MDRD & $15(14.2)$ & $130(24.5)$ & $90(37.7)$ & $59(56.2)$ & $21(53.8)$ & $12(40.0)$ & $<0.001$ \\
\hline CMDRD & $30(19.0)$ & $129(24.8)$ & $77(38.3)$ & $57(56.4)$ & $22(56.4)$ & $12(38.7)$ & $<0.001$ \\
\hline CKD-EPI & $14(18.7)$ & $125(23.9)$ & $77(35.3)$ & $63(49.2)$ & $31(47.0)$ & $17(42.5)$ & $<0.001$ \\
\hline Mayo & $36(15.7)$ & $155(29.8)$ & $51(37.2)$ & $47(56.6)$ & $25(53.2)$ & $13(38.2)$ & $<0.001$ \\
\hline \multicolumn{8}{|l|}{ Hypertension } \\
\hline MDRD & 76 (7I.7) & 407 (76.6) & 203 (84.9) & 90 (85.7) & 35 (89.7) & $28(93.3)$ & 0.001 \\
\hline CMDRD & I I 8 (74.7) & $398(76.5)$ & I73 (86.I) & $86(85.1)$ & 35 (89.7) & $29(93.5)$ & 0.002 \\
\hline CKD-EPI & $55(73.3)$ & $396(75.7)$ & $186(85.3)$ & $106(82.8)$ & $59(89.4)$ & $37(92.5)$ & 0.001 \\
\hline Mayo & $169(73.8)$ & $4 I I(79.0)$ & 116 (84.7) & 7I (85.5) & $40(85.1)$ & $32(94.1)$ & 0.014 \\
\hline \multicolumn{8}{|l|}{ DM (\%) } \\
\hline MDRD & $42(39.6)$ & 201 (37.9) & $98(41.0)$ & 44 (4I.9) & $23(59.0)$ & $9(30.0)$ & 0.137 \\
\hline CMDRD & $66(41.8)$ & 191 (36.7) & $84(41.8)$ & $44(43.6)$ & $22(56.4)$ & $10(32.3)$ & 0.133 \\
\hline CKD-EPI & $32(42.7)$ & $194(37.1)$ & $85(39.0)$ & $60(46.9)$ & $32(48.5)$ & $14(35.0)$ & 0.217 \\
\hline Mayo & $82(35.8)$ & $199(38.3)$ & $63(46.0)$ & $37(44.6)$ & $25(53.2)$ & II (32.4) & 0.097 \\
\hline \multicolumn{8}{|l|}{ AF (\%) } \\
\hline MDRD & $13(12.3)$ & I IO (20.7) & $60(25.1)$ & $17(16.2)$ & $13(33.3)$ & $6(20.0)$ & 0.029 \\
\hline CMDRD & $21(13.3)$ & $110(2 \mid .2)$ & $54(26.9)$ & $15(14.9)$ & $13(33.3)$ & $6(19.4)$ & 0.007 \\
\hline CKD-EPI & $5(6.7)$ & $107(20.5)$ & $58(26.6)$ & $22(17.2)$ & $18(27.3)$ & $9(22.5)$ & 0.006 \\
\hline Mayo & $37(16.2)$ & II4 (2I.9) & $34(24.8)$ & $12(14.5)$ & $16(34.0)$ & $6(17.6)$ & 0.036 \\
\hline
\end{tabular}

Abbreviations: GFR, glomerular filtration rate; MDRD, Modification of Diet in Renal Disease Study equation; CMDRD, Chinese MDRD equation; CKD-EPI, Chronic Kidney Disease Epidemiology Collaboration equation; Mayo, Mayo Clinic quadratic equation; BMI, body mass index; MSBP, mean systolic blood pressure; AMI, acute myocardial infarction; CHF, chronic heart failure; DM, diabetes mellitus; AF, atrial fibrillation.

According to the MDRD-GFR, CMDRD-GFR, CKDEPI-GFR, and Mayo-GFR, the prevalence of GFR $<60 \mathrm{~mL} /$ minute $/ 1.73 \mathrm{~m}^{2}$ in elderly patients with CAD was $39.3 \%$ (413 patients), 35.4\% (372 patients), 43.0\% (452 patients), and $28.7 \%$ (301 patients), respectively. Compared with the MDRD-GFR, the prevalence of GFR $<60 \mathrm{~mL} / \mathrm{min}$ ute $/ 1.73 \mathrm{~m}^{2}$, according to the CMDRD-GFR (kappa value: 0.917, $P<0.001$ ), CKD-EPI-GFR (kappa value: 0.908 , $P<0.001$ ), and Mayo-GFR (kappa value: $0.761, P<0.001$ ) showed significant differences. The number of patients in the 
A

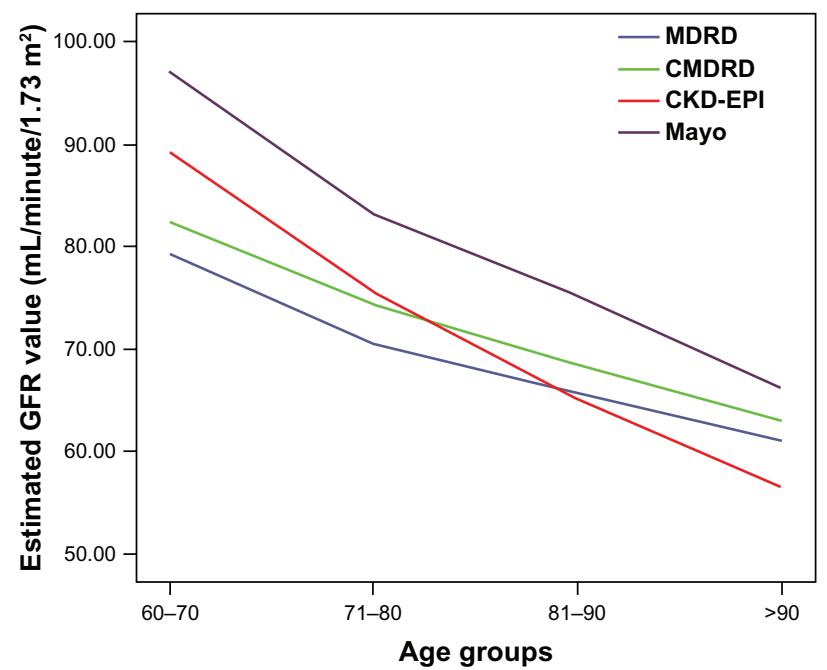

B

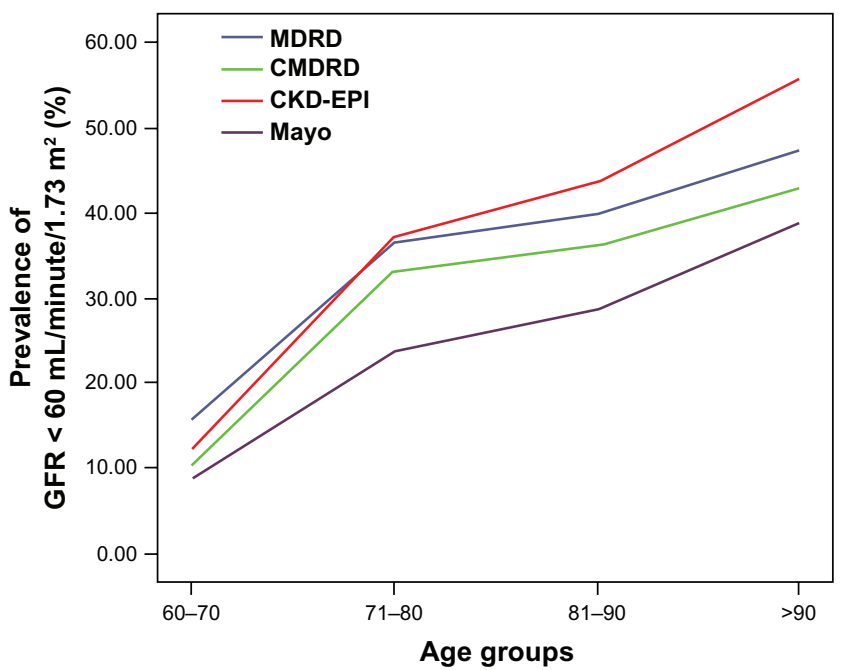

Figure I GFR determined by each equation and prevalence of a GFR $<60 \mathrm{~mL} /$ minute/l.73 $\mathrm{m}^{2}$. (A) The GFR determined by each equation decreased as the I0-year age categories increased. (B) The prevalence of a GFR $<60 \mathrm{~mL} /$ minute/l.73 $\mathrm{m}^{2}$ was proportional to the I0-year age categories.

Abbreviations: GFR, glomerular filtration rate; MDRD, Modification of Diet in Renal Disease Study equation; CMDRD, Chinese MDRD equation; CKD-EPI, Chronic Kidney Disease Epidemiology Collaboration equation; Mayo, Mayo Clinic quadratic equation.

different GFR categories is reported in Table 2. The prevalence of GFR $<60 \mathrm{~mL} /$ minute $/ 1.73 \mathrm{~m}^{2}$ was proportional to the 10-year age categories (Figure 1B).

There was a mean follow-up period of 417 days (median: 319 days; 25th-75th percentiles: 185-557 days) for the entire cohort, with 218 deaths (20.8\%). The mortality rates for each GFR category are displayed in Table 2 . The mortality rates of the patients with a GFR $<60 \mathrm{~mL} /$ minute $/ 1.73 \mathrm{~m}^{2}$ determined by the MDRD, CMDRD, CKD-EPI, and Mayo equations were 8.6\% (118 patients), $30.1 \%$ (112 patients), $28.5 \%$ (129 patients), and 33.6\% (101 patients), respectively. Compared with the MDRD equation, the mortality rates of the patients with a GFR $<60 \mathrm{~mL} /$ minute $/ 1.73 \mathrm{~m}^{2}$ determined by other equations had no clear difference (CMDRD equation: $P=0.637$; CKD-EPI equation: $P=0.992$; Mayo equation: $P=0.154)$. The AUC values for predicting death with respect to the MDRD-GFR, CMDRD-GFR, CKD-EPI-GFR, and Mayo-GFR were 0.611 [95\% confidence interval (CI): 0.563-0.659], 0.610 (95\% CI: 0.562-0.658), 0.625 (95\% CI: 0.579-0.672), and 0.632 (95\% CI: 0.586-0.677), respectively. Despite no significant difference between the MDRD-GFR and CMDRD-GFR $(P=0.651)$, the AUC values of the CKD-EPI-GFR and Mayo-GFR varied significantly from the MDRD-GFR and CMDRD-GFR (all $P<0.001$ ). Compared with the CKDEPI-GFR, a larger but statistically insignificant AUC value was observed with the Mayo-GFR $(P=0.244)$. The cut-off points for the MDRD-GFR, CMDRD-GFR, CKD-EPI-GFR, and Mayo-GFR with the best accuracy for predicting death were at $54.1 \mathrm{~mL} /$ minute $/ 1.73 \mathrm{~m}^{2}$ (sensitivity: 0.762 ; speci-

Table 2 Numbers of patients and mortality rates at each GFR category

\begin{tabular}{|c|c|c|c|c|c|c|}
\hline \multirow[t]{2}{*}{ Characteristics } & \multicolumn{6}{|c|}{ GFR categories (mL/minute/l. $\left.73 \mathrm{~m}^{2}\right)$} \\
\hline & $>90$ & $60-89$ & $45-59$ & $30-44$ & $15-29$ & $<\mathbf{I 5}$ \\
\hline \multicolumn{7}{|c|}{ Numbers of patients (\%) } \\
\hline MDRD & $106(10.1)$ & $531(50.6)$ & $239(22.8)$ & $105(10.0)$ & $39(3.7)$ & $30(2.9)$ \\
\hline CMDRD & $158(15.0)$ & $520(49.5)$ & $201(19.1)$ & $101(9.6)$ & $39(3.7)$ & $31(3.0)$ \\
\hline CKD-EPI & $75(7.1)$ & $523(49.8)$ & $218(20.8)$ & $128(12.2)$ & $66(6.3)$ & $40(3.8)$ \\
\hline Mayo & $229(21.8)$ & $520(49.5)$ & $137(13.0)$ & $83(7.9)$ & $47(4.5)$ & $34(3.2)$ \\
\hline \multicolumn{7}{|l|}{ Mortality rates (\%) } \\
\hline MDRD & $28(26.4)$ & $72(13.6)$ & $42(17.6)$ & $38(36.2)$ & $20(51.3)$ & $18(60.0)$ \\
\hline CMDRD & $37(23.4)$ & $69(13.3)$ & $39(19.4)$ & $35(34.7)$ & $19(48.7)$ & $19(61.3)$ \\
\hline CKD-EPI & $15(20.0)$ & 74 (I4.I) & $42(19.3)$ & $36(28.1)$ & $27(40.9)$ & $24(60.0)$ \\
\hline Mayo & 40 (I7.5) & 77 (I4.8) & 30 (21.9) & $26(31.3)$ & 24 (5I.I) & 21 (6I.8) \\
\hline
\end{tabular}

Abbreviations: GFR, glomerular filtration rate; MDRD, Modification of Diet in Renal Disease Study equation; CMDRD, Chinese MDRD equation; CKD-EPI, Chronic Kidney Disease Epidemiology Collaboration equation; Mayo, Mayo Clinic quadratic equation. 
ficity: 0.477 ), $53.5 \mathrm{~mL} / \mathrm{minute} / 1.73 \mathrm{~m}^{2}$ (sensitivity: 0.797 ; specificity: 0.450$), 48.0 \mathrm{~mL} / \mathrm{minute} / 1.73 \mathrm{~m}^{2}$ (sensitivity: 0.787; specificity: 0.463 ), and $57.4 \mathrm{~mL} /$ minute $/ 1.73 \mathrm{~m}^{2}$ (sensitivity: 0.791; specificity: 0.454), respectively.

Compared with the MDRD-GFR, the CMDRD-GFR reclassified two $(0.2 \%)$ to higher, and $96(9.1 \%)$ to lower categories, the CKD-EPI-GFR reclassified 202 (19.2\%) to higher, and 25 (2.4\%) to lower categories, and the MayoGFR reclassified 38 (3.6\%) to higher, and 268 (25.5\%) to lower categories. Compared with the CKD-EPI-GFR, the Mayo-GFR reclassified $22(2.1 \%)$ to higher and $429(40.9 \%)$ to lower categories. The reclassification of patients in different GFR categories is shown in Table 3. The NRI in the risk of mortality was calculated and shown in Table 4. Compared with the MDRD-GFR and CMDRDGFR, the NRI of the CKD-EPI-GFR was calculated at 0.10 and 0.09 , and was highly significant $(P=0.004$ and $P<0.001)$. Similar results were observed for the MayoGFR (NRI: 0.14, $P<0.001$; NRI: 0.12, $P<0.001$ ); however, there was no significant distinction in the NRI between the MDRD-GFR and CMDRD-GFR (NRI: 0.02, $P=0.258)$ or between the CKD-EPI-GFR and Mayo-GFR (NRI: $0.04, P=0.221$ ).

Based on univariate analysis, a GFR $<60 \mathrm{~mL} / \mathrm{min}-$ ute/1.73 $\mathrm{m}^{2}$ was associated with mortality regardless of the equation used (MDRD-GFR, HR: 1.98, 95\% CI: 1.52-2.59, $P<0.001$; CMDRD-GFR, HR: 2.14 , 95\% CI:
1.64-2.79, $P<0.001$; CKD-EPI-GFR, HR: $2.10,95 \% \mathrm{CI}:$ 1.60-2.75, $P<0.001$; Mayo-GFR, HR: 2.46, 95\% CI: 1.88-3.20, $P<0.001)$. The associations of the MDRDGFR $<54.1 \mathrm{~mL} / \mathrm{minute} / 1.73 \mathrm{~m}^{2}$ (HR: 2.58, 95\% CI: 1.98-3.37, $P<0.001)$, CMDRD-GFR $<53.5 \mathrm{~mL} / \mathrm{min}-$ ute $/ 1.73 \mathrm{~m}^{2}$ (HR: 2.76, 95\% CI: 2.11-3.60, $P<0.001$ ), CKD-EPI-GFR $<48.0 \mathrm{~mL} / \mathrm{minute} / 1.73 \mathrm{~m}^{2}$ (HR: 2.75, 95\% CI: $2.11-3.60, P<0.001)$, and Mayo-GFR $<57.4 \mathrm{~mL} /$ minute/1.73 $\mathrm{m}^{2}$ (HR: 2.73, 95\% CI: 2.09-3.56, $P<0.001$ ) with higher mortality were all stronger. After adjusting for age, gender, CHF, acute myocardial infarction, $\mathrm{AF}$, hypertension, diabetes mellitus, body mass index, and mean systolic blood pressure, patients with a GFR $<60 \mathrm{~mL} / \mathrm{minute} / 1.73 \mathrm{~m}^{2}$ experienced a significantly higher mortality than patients with a GFR $\geq 60 \mathrm{~mL} / \mathrm{min}$ ute/1.73 m² (MDRD-GFR, HR: 1.57, 95\% CI: 1.19-2.07, $P=0.002$; CMDRD-GFR, HR: 1.63, 95\% CI: 1.23-2.15, $P=0.001$; CKD-EPI-GFR, HR: 1.62, 95\% CI: 1.22-2.15, $P=0.001$; Mayo-GFR, HR: 1.86, 95\% CI: 1.40-2.46, $P<0.001)$. In addition, the MDRD-GFR $<54.1 \mathrm{~mL} /$ minute $/ 1.73 \mathrm{~m}^{2}$ (HR: 1.97, 95\% CI: $1.48-2.60, P<0.001$ ), CMDRD-GFR $<53.5 \mathrm{~mL} / \mathrm{minute} / 1.73 \mathrm{~m}^{2}$ (HR: 2.07, 95\% CI: 1.54-2.75, $P<0.001)$, CKD-EPI-GFR $<48.0 \mathrm{~mL} /$ minute $/ 1.73 \mathrm{~m}^{2}$ (HR: 2.05, 95\% CI: 1.54-2.72, $P<0.001$ ), and Mayo-GFR $<57.4 \mathrm{~mL} / \mathrm{minute} / 1.73 \mathrm{~m}^{2}$ (HR: 2.05, 95\% CI: $1.54-2.72, P<0.001)$ showed more identifiable relationships with mortality.

Table 3 The reclassification of patients at different GFR categories

\begin{tabular}{|c|c|c|c|c|c|c|c|}
\hline $\begin{array}{l}\text { GFR } \\
\left(\mathrm{mL} / \text { minute/ } / .73 \mathrm{~m}^{2}\right)\end{array}$ & Reclassification & $\begin{array}{l}\text { CMDRD }^{\mathrm{a}} \\
\text { (MDRD) }\end{array}$ & $\begin{array}{l}\text { CKD-EPI } \\
\text { (MDRD) }\end{array}$ & $\begin{array}{l}\text { Mayo } \\
\text { (MDRD) }\end{array}$ & $\begin{array}{l}\text { CKD-EPI } \\
\text { (CMDRD) }\end{array}$ & $\begin{array}{l}\text { Mayo } \\
\text { (CMDRD) }\end{array}$ & $\begin{array}{l}\text { Mayo } \\
\text { (CKD-EPI) }\end{array}$ \\
\hline \multirow[t]{3}{*}{$>90$} & Upward ${ }^{\mathrm{b}}$ & 0 & 0 & 0 & 0 & 0 & 0 \\
\hline & Unchanged & 106 & 54 & 84 & 67 & 128 & 53 \\
\hline & Downward ${ }^{c}$ & 0 & 52 & 22 & 91 & 30 & 22 \\
\hline \multirow[t]{3}{*}{$60-89$} & Upward & 52 & 21 & 145 & 8 & 101 & 176 \\
\hline & Unchanged & 479 & 467 & 386 & 432 & 419 & 347 \\
\hline & Downward & 0 & 43 & 0 & 80 & 0 & 0 \\
\hline \multirow[t]{3}{*}{$45-59$} & Upward & $4 I$ & 4 & 113 & 0 & 72 & 152 \\
\hline & Unchanged & 198 & 175 & 126 & 138 & 128 & 66 \\
\hline & Downward & 0 & 60 & 0 & 63 & I & 0 \\
\hline \multirow[t]{3}{*}{$30-44$} & Upward & 3 & 0 & 10 & 0 & 8 & 70 \\
\hline & Unchanged & 101 & 68 & 83 & 65 & 82 & 58 \\
\hline & Downward & I & 37 & 12 & 36 & 11 & 0 \\
\hline \multirow[t]{3}{*}{$15-29$} & Upward & 0 & 0 & 0 & 0 & 0 & 25 \\
\hline & Unchanged & 38 & 29 & 35 & 30 & 36 & 41 \\
\hline & Downward & 1 & 10 & 4 & 9 & 3 & 0 \\
\hline \multirow[t]{3}{*}{$<15$} & Upward & 0 & 0 & 0 & 0 & 0 & 6 \\
\hline & Unchanged & 30 & 30 & 30 & 31 & 31 & 34 \\
\hline & Downward & 0 & 0 & 0 & 0 & 0 & 0 \\
\hline
\end{tabular}

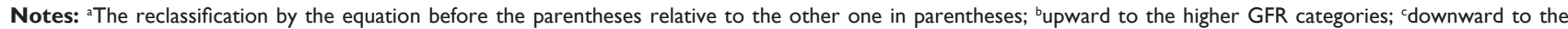
lower GFR categories.

Abbreviations: GFR, glomerular filtration rate; MDRD, Modification of Diet in Renal Disease Study equation; CMDRD, Chinese MDRD equation; CKD-EPI, Chronic Kidney Disease Epidemiology Collaboration equation; Mayo, Mayo Clinic quadratic equation. 
Table 4 The net reclassification improvement in risk of mortality

\begin{tabular}{|c|c|c|c|c|c|c|}
\hline \multirow{2}{*}{$\begin{array}{l}\text { Equation } \\
\text { comparisons }\end{array}$} & \multicolumn{2}{|c|}{ Appropriate move } & \multicolumn{2}{|c|}{ Inappropriate move } & \multirow[t]{2}{*}{$\mathbf{N R I ^ { \mathbf { a } }}$} & \multirow[t]{2}{*}{$P$-value } \\
\hline & $\begin{array}{l}\text { Upward/ } \\
\text { survived }\end{array}$ & $\begin{array}{l}\text { Downward/ } \\
\text { died }\end{array}$ & $\begin{array}{l}\text { Downward/ } \\
\text { survived }\end{array}$ & $\begin{array}{l}\text { Upward/ } \\
\text { died }\end{array}$ & & \\
\hline CMDRD (MDRD) ${ }^{\mathrm{b}}$ & $(78 / 832+$ & $1 / 2 \mid 8)$ & $-(1 / 832$ & $+(8 / 218)$ & 0.02 & 0.258 \\
\hline CKD-EPI (MDRD) & $(24 / 832+$ & $55 / 218)$ & $-(147 / 832$ & $+(/ 218)$ & 0.10 & 0.004 \\
\hline Mayo (MDRD) & $(227 / 832+$ & $|7 / 2| 8)$ & $-(21 / 832$ & $+4 I / 2 \mid 8)$ & 0.14 & $P<0.001$ \\
\hline CKD-EPI (CMDRD) & $(8 / 832+$ & $71 / 218)$ & $-(208 / 832$ & $+0 / 218)$ & 0.09 & $P<0.001$ \\
\hline Mayo (CMDRD) & (I56/832+ & $18 / 218)$ & $-(27 / 832$ & $+25 / 218)$ & 0.12 & $P<0.001$ \\
\hline Mayo (CKD-EPI) & $(346 / 832+$ & $5 / 218)$ & $-(17 / 832$ & $+83 / 218)$ & 0.04 & 0.221 \\
\hline
\end{tabular}

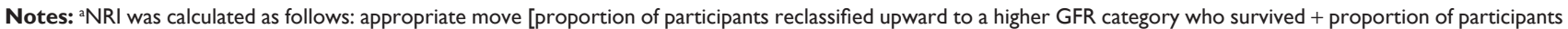
reclassified downward to a lower GFR category who died] - inappropriate move [proportion of participants reclassified downward to a lower GFR category who survived + proportion of participants reclassified upward to a higher GFR category who died]. The GFR was divided into six different categories, including $>90,60-89,45-59,30-44$, $15-29$, and $<15 \mathrm{~mL} /$ minutes $/ 1.73 \mathrm{~m}^{2}$. The $Z$ statistic was used to determine the significance of NRI; ${ }^{\text {bthe }} \mathrm{NRI}$ of the equation before the parentheses relative to the other one in parentheses.

Abbreviations: CMDRD, Chinese Modification of Diet in Renal Disease equation; MDRD, Modification of Diet in Renal Disease study equation; CKD-EPI, Chronic Kidney Disease Epidemiology Collaboration equation; Mayo, Mayo Clinic quadratic equation; NRI, net reclassification improvement; GFR, glomerular filtration rate.

\section{Discussion}

The NHANES study has shown that there is a higher level of GFR and a lower prevalence of renal function impairment in the general population when using the CKD-EPI equation compared with the MDRD equation, ${ }^{19}$ but in the light of a recent study directed at the elderly, the result appeared to be the opposite for the elderly. ${ }^{20}$ Similarly, we found in elderly Chinese that the order of the median GFR from high to low was the Mayo-GFR, CMDRD-GFR, MDRD-GFR, and EPIGFR. The order of GFR $<60 \mathrm{~mL} /$ minute $/ 1.73 \mathrm{~m}^{2}$ prevalence from high to low was the CKD-EPI-GFR, MDRD-GFR, CMDRD-GFR, and Mayo-GFR. Previous trials with the general population as the study subjects mainly attributed the higher level of GFR and a lower prevalence of renal function impairment using the CKD-EPI equation to the subgroups at low risk for CKD (age $<60$ years, women, and white subjects). For these subgroups, there were lower levels of GFR and a higher prevalence of renal function impairment according to the MDRD equation. ${ }^{21}$ Our study was aimed directly at the elderly Chinese with CAD, who tended to be older, male, and at high risk for renal function impairment.

Recent studies have shown that people at lower risk for renal function impairment, such as women, younger, and white subjects, were mainly reclassified to lower GFR categories using the CKD-EPI equation and had a lower risk of death, indicating that the CKD-EPI equation improved categorization concerning mortality compared with the MDRD equation. ${ }^{21-24}$ However, the better reclassification of the CKD-EPI was not validated by another study with a focus on the elderly. ${ }^{25}$ In the current study, the AUC and NRI values showed that the prognostic abilities of the EPIGFR and Mayo-GFR were far superior to the MDRD-GFR and CMDRD-GFR. Moreover, even without statistical significance, the Mayo equation still categorized individuals more appropriately than the CKD-EPI equation and might better predict adverse outcomes.

Several studies, such as the Health, Aging, and Body Composition study, showed that a GFR $<60 \mathrm{~mL} / \mathrm{min}-$ ute $/ 1.73 \mathrm{~m}^{2}$ compared with a GFR $>60 \mathrm{~mL} /$ minute $/ 1.73 \mathrm{~m}^{2}$, was a strong predictor of cardiovascular death. ${ }^{26}$ However, Go et $\mathrm{al}^{27}$ believed that a GFR $<45 \mathrm{~mL} /$ minute $/ 1.73 \mathrm{~m}^{2}$, rather than a GFR $<60 \mathrm{~mL} /$ minute $/ 1.73 \mathrm{~m}^{2}$, was the threshold below which all-cause mortality significantly increased. In addition, the Alberta Provincial Project for Outcomes Assessments in Coronary Heart Disease (APPROACH) Registry proposed that a GFR $<79 \mathrm{~mL} /$ minute $/ 1.73 \mathrm{~m}^{2}$, but not a GFR $>90 \mathrm{~mL} /$ minute $/ 1.73 \mathrm{~m}^{2}$, was the cut-off value for a significant increase in all-cause mortality. ${ }^{28} \mathrm{In}$ fact, all of the studies transformed the GFR to a categorical variable with the levels set in advance, compared the correlation of different categories with mortality, and selected one preset level as the cut-off point, which was limited by the subjective factor. Unlike those studies, the current study used the GFR as a continuous variable and defined the cut-off value with the ROC curve, showing stronger objectivity and accuracy, which demonstrated that even with the presence of better cut-off values, a GFR $<60 \mathrm{~mL} /$ minute $/ 1.73 \mathrm{~m}^{2}$ was still a significant predictor of mortality, independent of which equation was used. The National Kidney Foundation acknowledged that identifying subjects with impaired renal function based on the GFR, without reference to age, gender, race, and comorbidity, might lead to an inappropriate prognostic assessment of CKD. ${ }^{29}$ For elderly Chinese patients with $\mathrm{CAD}$, the current study demonstrated that the optimal cut-off values to predict a significant increase in mortality were set at $54.1 \mathrm{~mL} /$ minute $/ 1.73 \mathrm{~m}^{2}$ for the MDRD-GFR, 
$53.5 \mathrm{~mL} / \mathrm{minute} / 1.73 \mathrm{~m}^{2}$ for the CMDRD-GFR, $48.0 \mathrm{~mL} /$ minute/1.73 $\mathrm{m}^{2}$ for the CKD-EPI-GFR, and $57.4 \mathrm{~mL} /$ minute/ $1.73 \mathrm{~m}^{2}$ for the Mayo-GFR.

To summarize, the prognostic abilities of the CKDEPI and Mayo equations were significantly superior to the MDRD and CMDRD equations, and the Mayo equation had a mild, but not statistically significant superiority compared with the CKD-EPI equation in elderly Chinese patients with CAD. Although a GFR $<60 \mathrm{~mL} /$ minute $/ 1.73 \mathrm{~m}^{2}$ was still an independent predictor of high mortality independent of which equation was used, the optimal GFR cut-off values indicating a significant increase in mortality were set at $54.1 \mathrm{~mL} /$ minute $/ 1.73 \mathrm{~m}^{2}$ for the MDRD-GFR, $53.5 \mathrm{~mL} / \mathrm{minute} / 1.73 \mathrm{~m}^{2}$ for the CMDRD-GFR, $48.0 \mathrm{~mL} /$ minute/1.73 $\mathrm{m}^{2}$ for the CKD-EPI-GFR, and $57.4 \mathrm{~mL} /$ minute/ $1.73 \mathrm{~m}^{2}$ for the Mayo-GFR.

\section{Acknowledgment}

The study was supported by the Central Health Special Foundation (Beijing, People's Republic of China).

\section{Disclosure}

The authors report no conflicts of interest in this work.

\section{References}

1. Liu H, Yu J, Chen F, Li J, Hu D. Inpatients with coronary heart disease have a high prevalence of chronic kidney disease based on estimated glomerular filtration rate (eGFR) in China. Heart Vessels. 2007;22(4): 223-228.

2. Moe SM, Chen NX. Mechanisms of vascular calcification in chronic kidney disease. J Am Soc Nephrol. 2008;19(2):213-216.

3. Anavekar NS, McMurray JJ, Velazquez EJ, et al. Relation between renal dysfunction and cardiovascular outcomes after myocardial infarction. N Engl J Med. 2004;351(13):1285-1295.

4. Manjunath G, Tighiouart $\mathrm{H}$, Coresh $\mathrm{J}$, et al. Level of kidney function as a risk factor for cardiovascular outcomes in the elderly. Kidney Int. 2003;63(3):1121-1129.

5. Levey AS, Bosch JP, Lewis JB, Greene T, Rogers N, Roth D. A more accurate method to estimate glomerular filtration rate from serum creatinine: a new prediction equation. Ann Intern Med. 1999;130(6): 461-470.

6. Stevens LA, Coresh J, Feldman HI, et al. Evaluation of the modification of diet in renal disease study equation in a large diverse population. J Am Soc Nephrol. 2007;18(10):2749-2757.

7. Glassock RJ. Referrals for chronic kidney disease: real problem or nuisance? JAMA. 2010;303(12):1201-1203.

8. Levey AS, Stevens LA, Schmid CH, et al; for CKD-EPI (Chronic Kidney Disease Epidemiology Collaboration). A new equation to estimate glomerular filtration rate. Ann Intern Med. 2009;150(9):604-612.

9. Stevens LA, Schmid CH, Zhang YL, et al. Development and validation of GFR-estimating equations using diabetes, transplant and weight. Nephrol Dial Transplant. 2010;25(2):449-457.

10. Rule AD, Larson TS, Bergstralh EJ, Slezak JM, Jacobsen SJ, Cosio FG. Using serum creatinine to estimate glomerular filtration rate: accuracy in good health and in chronic kidney disease. Ann Intern Med. 2004;141(12):929-937.
11. Ma YC, Zuo L, Chen JH, et al. Modified glomerular filtration rate estimating equation for Chinese patients with chronic kidney disease. J Am Soc Nephrol. 2006;17(10):2937-2944.

12. Poggio ED, Rule AD. A critical evaluation of chronic kidney disease - should isolated reduced estimated glomerular filtration rate be considered a 'disease'? Nephrol Dial Transplant. 2009;24(3): 698-700.

13. Fox K, Garcia MA, Ardissino D, et al; Task Force on the Management of Stable Angina Pectoris of the European Society of Cardiology, ESC Committee for Practice Guidelines (CPG). Guidelines on the management of stable angina pectoris: executive summary: The Task Force on the Management of Stable Angina Pectoris of the European Society of Cardiology. Eur Heart J. 2006;27(23):1341-1381.

14. Thygesen K, Alpert JS, White HD, et al; for Joint ESC/ACCF/AHA/WHF Task Force for the Redefinition of Myocardial Infarction. Universal definition of myocardial infarction. Circulation. 2007;116(22): 2634-2653.

15. Zhang L, Zuo L, Xu G, et al. Community-based screening for chronic kidney disease among populations older than 40 years in Beijing. Nephrol Dial Transplant. 2007;22(4):1093-1099.

16. Fuster V, Rydén LE, Cannom DS, et al; for American College of Cardiology/American Heart Association Task Force on Practice Guidelines, European Society of Cardiology Committee for Practice Guidelines, European Heart Rhythm Association, Heart Rhythm Society. ACC/AHA/ESC 2006 Guidelines for the Management of Patients with Atrial Fibrillation: a report of the American College of Cardiology/ American Heart Association Task Force on Practice Guidelines and the European Society of Cardiology Committee for Practice Guidelines (Writing Committee to Revise the 2001 Guidelines for the Management of Patients With Atrial Fibrillation): developed in collaboration with the European Heart Rhythm Association and the Heart Rhythm Society. Circulation. 2006;114(7):e257-e354.

17. Dickstein K, Cohen-Solal A, Filippatos G, et al; for ESC Committee for Practice Guidelines (CPG). ESC Guidelines for the diagnosis and treatment of acute and chronic heart failure 2008: the Task Force for the Diagnosis and Treatment of Acute and Chronic Heart Failure 2008 of the European Society of Cardiology. Developed in collaboration with the Heart Failure Association of the ESC (HFA) and endorsed by the European Society of Intensive Care Medicine (ESICM). Eur Heart J. 2008;29(19):2388-2442.

18. Pencina MJ, D'Agostino RB Sr, D'Agostino RB Jr, Vasan RS. Evaluating the added predictive ability of a new marker: from area under the ROC curve to reclassification and beyond. Stat Med. 2008;27(2):157-172; discussion 207-212.

19. Jones CA, McQuillan GM, Kusek JW, et al. Serum creatinine levels in the US population: third National Health and Nutrition Examination Survey. Am J Kidney Dis. 1998;32(6):992-999.

20. Corsonello A, Pedone C, Lattanzio F, et al; for PharmacosurVeillance in the elderly Care study group. Chronic kidney disease and 1-year survival in elderly patients discharged from acute care hospitals: a comparison of three glomerular filtration rate equations. Nephrol Dial Transplant. 2011;26(1):360-364.

21. Stevens LA, Schmid CH, Greene T, et al. Comparative performance of the CKD Epidemiology Collaboration (CKD-EPI) and the Modification of Diet in Renal Disease (MDRD) Study equations for estimating GFR levels Above $60 \mathrm{~mL} / \mathrm{min} / 1.73 \mathrm{~m}^{2}$. Am J Kidney Dis. 2010;56(3): 486-495.

22. Matsushita K, Selvin E, Bash LD, Astor BC, Coresh J. Risk implications of the new CKD Epidemiology Collaboration (CKD-EPI) equation compared with the MDRD Study equation for estimated GFR: the Atherosclerosis Risk in Communities (ARIC) Study. Am J Kidney Dis. 2010;55(4):648-659.

23. White SL, Polkinghorne KR, Atkins RC, Chadban SJ. Comparison of the prevalence and mortality risk of CKD in Australia using the CKD Epidemiology Collaboration (CKD-EPI) and Modification of Diet in Renal Disease (MDRD) Study GFR estimating equations: the AusDiab (Australian Diabetes, Obesity and Lifestyle) Study. Am J Kidney Dis. 2010;55(4):660-670. 
24. Stevens LA, Li S, Kurella Tamura M, et al. Comparison of the CKD Epidemiology Collaboration (CKD-EPI) and Modification of Diet in Renal Disease (MDRD) study equations: risk factors for and complications of CKD and mortality in the Kidney Early Evaluation Program (KEEP). Am J Kidney Dis. 2011;57(3 Suppl 2):S9-S16.

25. Stengel B, Metzger M, Froissart M, et al. Epidemiology and prognostic significance of chronic kidney disease in the elderly - the Three-City prospective cohort study. Nephrol Dial Transplant. 2011;26(10): 3286-3295.

26. Deo R, Fyr CL, Fried LF, et al; for Health ABC study. Kidney dysfunction and fatal cardiovascular disease - an association independent of atherosclerotic events: results from the Health, Aging, and Body Composition (Health ABC) study. Am Heart J. 2008;155(1):62-68.
27. Go AS, Chertow GM, Fan D, McCulloch CE, Hsu CY. Chronic kidney disease and the risks of death, cardiovascular events, and hospitalization. N Engl J Med. 2004;351(13):1296-1305.

28. Hemmelgarn BR, Southern DA, Humphries KH, Culleton BF, Knudtson ML, Ghali WA; for Alberta Provincial Project for Outcomes Assessment in Coronary Heart Disease (APPROACH) Investigators. Refined characterization of the association between kidney function and mortality in patients undergoing cardiac catheterization. Eur Heart J. 2006;27(10):1191-1197.

29. Vassalotti JA, Stevens LA, Levey AS. Testing for chronic kidney disease: a position statement from the National Kidney Foundation. Am J Kidney Dis. 2007;50(2):169-180.
Clinical Interventions in Aging

\section{Publish your work in this journal}

Clinical Interventions in Aging is an international, peer-reviewed journal focusing on evidence-based reports on the value or lack thereof of treatments intended to prevent or delay the onset of maladaptive correlates of aging in human beings. This journal is indexed on PubMed Central, MedLine, the American Chemical Society's 'Chemical Abstracts Ser-

\section{Dovepress}

vice' (CAS), Scopus and the Elsevier Bibliographic databases. The manuscript management system is completely online and includes a very quick and fair peer-review system, which is all easy to use. Visit http://www.dovepress.com/testimonials.php to read real quotes from published authors.

Submit your manuscript here: http://www.dovepress.com/clinical-interventions-in-aging-journal 